\title{
A INTERNACIONALIZAÇÃO DA UNIVERSIDADE DE SÃO PAULO: RELAÇÕES ENTRE A DEMANDA ESTRANGEIRA E O ENSINO DE PORTUGUÊS COMO LÍNGUA ADICIONAL
}

\section{INTERNATIONALIZATION OF THE UNIVERSITY OF SÃO PAULO: RELATIONS BETWEEN THE FOREIGN DEMAND AND THE TEACHING OF PORTUGUESE AS AN ADDITIONAL LANGUAGE}

\author{
Leilane Morais Oliveira ${ }^{1}$
}

\begin{abstract}
RESUMO: Este artigo apresenta um estudo de caso ligado à Universidade de São Paulo (USP), por meio de uma discussão que relaciona dados da Agência USP de Cooperação Acadêmica e Internacional (AUCANI), referentes ao número de alunos estrangeiros recebidos por essa universidade, às ações que ela executa no âmbito do ensino de Português como Língua Adicional. De modo geral, os dados permitem notar que a gestão universitária tem avançado, no sentido de estabelecer ações ligadas ao ensino de língua portuguesa como parte de seu processo de internacionalização doméstica, seja via AUCANI ou via Centro de Linguas. Por outro lado, também permitem considerar que as ações ainda não são suficientes em termos quantitativos e em relação a abarcar níveis de ensino mais avançados do português brasileiro.
\end{abstract}

PALAVRAS-CHAVE: internacionalização doméstica; português como língua adicional; Oniversidade de São Paulo.

ABSTRACT: This article presents a case study linked to the University of São Paulo (USP), through a discussion that relates data from the Agência USP de Cooperação Acadêmica e Internacional (AUCANI) referring to the number of foreign students received by this university and the actions that USP performs in the scope of teaching Portuguese as an Additional Language. In general, the data show that university management has advanced in order to establish actions linked to the teaching of Portuguese as part of its incoming internationalization process, either via AUCANI or through the Language Center. However, they also show that the actions are still not sufficient in quantitative terms and in relation to embracing the teaching of more advanced levels of Brazilian Portuguese.

KEYWORDS: IN internationalization; Portuguese as an additional language; University of São Paulo.

\section{Introdução}

Embora as trocas comerciais e culturais entre diferentes povos não representem ocorrências exclusivas dos tempos modernos - visto que já aconteciam antes de Cristo e foram potencializadas pelas grandes navegações da Renascença, bem como pela Revolução Industrial do século XVIII (WARNIER, 2000), é consenso que a globalização ampliou

\footnotetext{
${ }^{1}$ Doutora em Letras pela USP.
} 
consideravelmente a conectividade entre as pessoas e os estados-nação (RODRIGO-ALSINA; 1997; HALL, 2006), estreitando as distâncias, comprimindo o tempo e gerando novas formas de internacionalização de bens e de capital simbólico.

Como fruto de uma conjuntura de contraciclo ao sistema fordista de produção e distribuição de mercadorias, a globalização instaurou a Nova Economia: sistema que não somente anunciou a falência do modus operandi fordista, mas também permitiu a discussão de lógicas produtivas mais compatíveis com uma economia aberta (OLIVEIRA, 2010, 2013; BERGER, 2013).

A comunicação, nessa Nova Economia, adquiriu um lugar de centralidade em relação aos processos de mercado, tornando-se preponderante tanto para a inovação quanto para a comercialização dos bens. A partir de então, várias mudanças estabeleceram uma nova organização social (chamada de Sociedade do Conhecimento), a qual impulsionou a produção e a disseminação de informações, reconhecendo o saber como capital humano. Essa concepção, por sua vez, levou diferentes línguas a serem vistas como capital, como meios de produção, e de aquisição e/ou manutenção de poder (ALBUQUERQUE; ESPERANÇA, 2010; OLIVEIRA, 2013).

Nesta Sociedade do Conhecimento, a globalização estabeleceu novas demandas e agendas, dentre as quais se encontra a internacionalização de capital econômico e de capital simbólico ${ }^{2}$. Nesse contexto, um ambiente multilíngue e multicultural se configurou, de modo que o conhecimento de outras línguas tornou-se um imperativo para muitos setores da sociedade, o que fez surgir uma onda de internacionalizações linguísticas.

Nesse novo paradigma, a comunicação, a linguagem e o discurso ocupam um lugar de extrema relevância por estarem tanto no cerne das relações produtivas quanto ligadas à construção da identidade social, cultural e política dos indivíduos. Como consequência disso, o multilinguismo vem ganhando cada vez mais importância nas diferentes esferas do mundo contemporâneo, de modo que atores sociais diversos e também o Estado passam a questionar a ideologia monolíngue. Assim, as línguas e seu gerenciamento vêm ocupando papel central no mundo todo, de modo que governos e outros atores sociais têm investido cada vez mais em reformas no ensino, elaboração de novos currículos, oficialização de novas línguas, financiamento e elaboração de bancos de dados de línguas, entre outras ações (CARVALHO, 2012, p. 480).

\footnotetext{
2 Capital simbólico é um conceito usado por Bourdieu (2007) para a significação de bens que, na escala produtiva e de consumo do capitalismo, derivam de sistemas simbólicos - arte, linguagem, religião, cultura de modo geral. Dizem eles respeito a formas de lucro e poder que giram em torno da posse de elementos dotados de propriedades valorativas que, distinguindo-se de outros não possuidores dos mesmos atributos, são reconhecidos ou estigmatizados por indivíduos e/ou grupos, garantindo a perpetuação das relações de força que sustentam determinada ordem social vigente.
} 
A partir de especificidades e exigências apresentadas pelas forças produtivas, as instituições educacionais passaram por reformulações no sentido de fortalecer e/ou criar redes de cooperação internacional, seja a nível instrucional ou a nível de pesquisa, bem como de graduar alunos preparados para atuação na sociedade globalizada, o que inclui não somente conhecimento acadêmico e profissional, mas também habilidades sociais, de multilinguismo e de interculturalidade (QIANG, 2003).

Sendo assim, note-se que a globalização neoliberal e a internacionalização do ensino superior estão imbricadas. Esse fato, por sua vez, evidencia que muitas práticas podem sustentar uma comoditização $^{3}$ da educação, bem como formas imperialistas ou zonas de conforto ligadas a um capitalismo acadêmico, com potencial de garantir a hegemonia de certas instituições e de desprestigiar outras.

Neste caso, universidades de muitos países em desenvolvimento, como o Brasil, têm investido em programas com o objetivo de responder ativamente às necessidades que o mundo globalizado inexoravelmente impõe à educação superior. Essas iniciativas podem ser divididas em internacionalização do tipo $I N$, em que estudantes estrangeiros são recebidos no país e na(s) sede(s) da instituição de ensino, e $O U T$, ligada ao envio de estudantes locais às universidades estrangeiras ${ }^{4}$ (LIMA; MARANHÃO, 2009).

Knight (1997, p.11) disse que a internacionalização é considerada, por muitos professores e alunos de cursos de graduação e programas de pós-graduação, como uma importante ação para "preparação de graduados que possuem conhecimentos e habilidades robustas em comunicações e relações interculturais" ".

\footnotetext{
${ }^{3}$ Em muitos casos, o multilinguismo é, no interior dos processos de internacionalização acadêmica, apenas uma espécie de commodity. Assim, as línguas tornam-se uma forma de poder e o seu aprendizado serve apenas para responder às demandas da Sociedade do Conhecimento.

${ }^{4}$ Neste âmbito, a maior iniciativa brasileira deu-se pelo Ciências sem Fronteiras: "programa do Governo Federal que busca promover a consolidação, expansão e internacionalização da ciência e tecnologia, da inovação e da competitividade brasileira", sendo a sua atuação ligada à "mobilidade internacional docente, discente de graduação e pós-graduação, de pós-doutorandos e pesquisadores brasileiros” (BRASIL, 2019).

Para mais informações: http://www.capes.gov.br/cienciasemfronteiras/html/apresentacao.html

Acesso em: 6 mar. 2019.
}

${ }^{5}$ Tradução minha de: "The preparation of graduates who have a strong knowledge and skill base in intercultural relations and communications is considered by many academics as one of the strongest rationales for internationalizing the teaching/learning experience of students in undergraduate and graduate programs." (KNIGHT, 1997, p. 11) 
Esse processo de internacionalização, porém, não é novo, mas passou por uma intensificação na altura dos anos de 1980 (TAYLOR, 2010). Neste cenário, sobretudo o inglês, que é rotineiramente adotado como língua franca da ciência, permanece em relevo e o intercâmbio de pessoal docente/de alunos é, não raro no Brasil, dependente de proficiência linguística para a concessão de bolsas governamentais, de financiamentos da iniciativa privada etc.

Em relação ao inglês, Veiga (2011) aponta que muitas universidades o adotam como língua de trabalho, tanto nos laboratórios quanto nas salas de aula, utilizando-o com a intenção de facilitar os processos de internacionalização institucional e de divulgação das informações científicas, ainda que não tenham esse idioma como língua materna local. No entanto, isso é percebido pela autora como um risco, já que poderia implicar na não valorização da cultura linguística da sociedade em que a universidade está inserida.

A Universidade de São Paulo (doravante USP), diante desta realidade, mantém políticas linguísticas ligadas ao ensino do português brasileiro a estudantes estrangeiros que são recebidos, no campus da Cidade Universitária - localizado no município de São Paulo, para cursos de graduação ou de pós.

Diante disso, então, este trabalho objetiva apresentar um estudo de caso ligado à Universidade de São Paulo. Para isso, a discussão relaciona dados numéricos, recolhidos junto à Agência USP de Cooperação Acadêmica e Internacional (AUCANI) e referentes ao número de alunos estrangeiros recebidos pela USP, a ações da instituição para o ensino de Português como Língua Adicional ${ }^{6}$. O artigo encontra-se dividido da seguinte maneira: incialmente, apresenta-se um breve esboço teórico sobre o conceito de internacionalização acadêmica,

\footnotetext{
${ }^{6}$ Silva (2016) aponta que, na literatura moderna da área de português como língua estrangeira, há uma diferença considerável de nomenclaturas, a qual aponta para conceituações heterogêneas quanto à sua aplicação. A fim de esclarecer essa questão, retoma-se a fala do autor e expõe-se algumas das principais siglas e seus significados: PLE - Português Lingua Estrangeira, PE - Português para Estrangeiros, PSL - Português Segunda Língua, PLA - Português como Língua Adicional, PLA - Português Língua de Acolhimento, PLI - Português como Língua de Inclusão, e PLH - Português como Língua de Herança. PLE e PE foram as duas primeiras siglas a serem adotadas no interior dos estudos pioneiros em relação ao ensino e à aprendizagem de língua portuguesa nos Estados Unidos do século XVII. No esteio de avanços econômicos vivenciados no Brasil dos anos de 1990, surgiu o conceito de PSL, dado o aumento dos números de estrangeiros que, em território nacional, procuravam aprender a língua portuguesa. PLAdicional foi uma sigla cunhada para utilização sociolinguística, já que voltada ao âmbito de estudos relativos a indígenas brasileiros que, sendo falantes de suas línguas nativas, aprendem o português como idioma não materno. Entretanto, atualmente, esta passou a abranger qualquer cenário em que a língua portuguesa é aprendidada por alguém que já fala outra(s) língua(s). Ainda sob o prisma social, PLAcolhimento e PLI são conceitos que abrangem os processos de ensino-aprendizagem de português a populações de refugiados e imigrantes respectivamente. PLH, em contrapartida, diz respeito a alunos que aprendem a língua portuguesa em virtude de ser ela utilizada em seu lar (já que seus pais seriam lusofalantes), mas não o idioma da sociedade em que vivem. Opta-se, neste estudo, por PLAadicional, em virtude de ser uma sigla que generaliza o processo de, em contexto de imersão e/ou de não imersão, ensinar e aprender a língua portuguesa como idioma que se soma a outros já dominados por um falante.
} 
seguido pela discussão dos dados e, finalmente, de algumas considerações ligadas ao que se depreende do estudo realizado.

\section{Internacionalização acadêmica}

Morosini (2006) sugere que o termo internacionalização do ensino superior (ou internacionalização acadêmica) é epistemologicamente complexo, porque caracterizado por certa imprecisão relativa às diversas perspectiva sob as quais o fenômeno pode ser observado. Aqui, adota-se a perspectiva segundo a qual internacionalização, em ambientes universitários, refere-se a um conjunto de ações destinadas à criação de processos educativos estabelecidos em uma perspectiva global (KNIGHT; DE WIT, 1995).

Logo, internacionalização, no ambiente universitário, refere-se a quaisquer esforços relacionados a tornar o ensino superior preparado, em termos de formação de pessoal, para o cenário social que caracteriza o mundo globalizado. Conforme exposto na introdução, é preciso considerar que a internacionalização acadêmica está profundamente imbricada ao processo de globalização e, consequentemente, às determinações de organismos internacionais ligados à educação.

A partir de Veiga (2011), tem-se que a internacionalização de uma instituição de ensino superior pode ser entendida a partir de perspectivas que variam em conformidade com a abordagem adotada. Conforme síntese que a autora realizou a partir do estudo de Knight (2011), essas abordagens são: 1. Atividade - a internacionalização é descrita a partir das ações desenvolvidas pela instituição universitária, tais como envio de pessoal para o exterior, currículo e programas acadêmicos, ligações e redes institucionais, desenvolvimento de projetos em cooperação etc.; 2. Resultados - abordagem que apresenta a internacionalização a partir de dados ligados à ampliação das competências dos alunos, número de acordos travados, parceiros de pesquisa, dentre outros; 3. Motivações - entende o processo de internacionalização a partir das motivações primárias que o conduzem, tais como criação de um ambiente universitário multicultural, geração de rendimento, aperfeiçoamento de pessoal etc.; 4. Processo - integra a internacionalização, de maneira sustentável, às três funções primárias de uma universidade, a saber, ao ensino, à pesquisa e à extensão; 5. Caráter processo que entende a internacionalização como o estabelecimento de uma cultura ou de um clima no ambiente universitário, os quais se relacionam à promoção e sustentação da 
interculturalidade no ambiente local; e 6. Estrangeira/ além das fronteiras - abordagem em que a educação superior local enfatiza iniciativas provenientes de instituições estrangeiras, acentuando a mobilidade.

É claro que o destaque conferido a uma dessas abordagens (ou a algumas delas) é dependente do que caracteriza a atuação das diversas partes envolvidas no processo, tais como o governo, os sujeitos a cargo da gestão institucional, os membros da instituição, a grade curricular etc. (JOFIN, 2009).

No caso da Universidade de São Paulo, nota-se que várias dessas abordagens parecem guiar, em simbiose, a atuação da Agência USP de Cooperação Acadêmica e Internacional (AUCANI), uma vez o objetivo da agência é estabelecer laços de cooperação nacionais/internacionais entre a USP, instituições universitárias, órgãos públicos e sociedade. Sendo assim, o trabalho da AUCANI volta-se ao suporte de ações de ensino, pesquisa, cultura e extensão universitária, o que se dá a partir de três diretorias: relações acadêmicas internacionais, relações acadêmicas nacionais e mobilidade acadêmica. Assim, a seguir, apresento e discuto dados relacionados à USP e ao ensino de língua portuguesa no contexto de sua internacionalização doméstica, ou seja, das atividades locais/internas que possuem dimensão internacional, mas não relacionada à mobilidade de professores/estudantes para o exterior.

\section{Políticas de Internacionalização Linguística da Universidade de São Paulo (USP)}

A Universidade de São Paulo, fundada em 1934, é mantida pelo governo do Estado de São Paulo, via Secretaria de Desenvolvimento Econômico, e mantém campi nas cidades de São Paulo, Bauru, Lorena, Piracicaba, Pirassununga, Ribeirão Preto, Santos e São Carlos, além de possuir unidades de ensino, museus e centros de pesquisa situados em diferentes municípios. A instituição fornece 183 opções de cursos de graduação e conta com 239 programas de pós-graduação, atendendo a 58 mil alunos na formação inicial e a 30 mil na continuada ${ }^{7}$. Por meio da AUCANI, a USP promove políticas linguísticas no sentido de internacionalizar a língua portuguesa. Nesse sentido, a sequência do texto apresenta uma compilação de dados fornecidos pela própria Agência à autora do estudo. Três tabelas expõem então o número de

\footnotetext{
${ }^{7}$ Para mais informações sobre a Universidade de São Paulo: https://www5.usp.br/institucional/a-usp/ Acesso em: 17 mar. 2019.
} 
alunos que, entre os anos de 2010 e 2017, foram recebidos na USP para cada uma das modalidades citadas.

De modo geral, o maior número de estudantes estrangeiros que a USP recebe é proveniente dos convênios firmados no âmbito dos intercâmbios, os quais são realizados para a graduação e a pós-graduação. Os números absolutos, por país de origem, são os seguintes:

\begin{tabular}{|c|c|c|c|c|c|c|c|c|}
\hline \multicolumn{9}{|c|}{ Intercâmbio } \\
\hline País & 2010 & 2011 & 2012 & 2013 & 2014 & 2015 & 2016 & 2017 \\
\hline África do Sul & - & - & - & - & - & - & 1 & - \\
\hline Alemanha & 64 & 96 & 129 & 116 & 127 & 107 & 101 & 90 \\
\hline Angola & 10 & - & 9 & 4 & 5 & - & - & - \\
\hline Argentina & 20 & 34 & 37 & 49 & 36 & 10 & 11 & 10 \\
\hline Austrália & - & 2 & - & - & 1 & - & - & - \\
\hline Áustria & 2 & 2 & 4 & 5 & 6 & 6 & 8 & 5 \\
\hline Bélgica & 10 & 12 & 12 & 10 & 20 & 20 & 15 & 15 \\
\hline Bolívia & 1 & - & 1 & 1 & 2 & 5 & 1 & 4 \\
\hline Brasil & - & - & - & - & 1 & - & - & - \\
\hline Canadá & 7 & 9 & 4 & 6 & 7 & 4 & 7 & 8 \\
\hline Chile & 18 & 29 & 22 & 55 & 42 & 42 & 34 & 30 \\
\hline China & 6 & 18 & 11 & 23 & 34 & 47 & 32 & 34 \\
\hline Cingapura & - & - & - & - & - & - & 2 & 3 \\
\hline Colômbia & 104 & 133 & 138 & 148 & 166 & 156 & 162 & 168 \\
\hline $\begin{array}{l}\text { Coreia do } \\
\text { Sul }\end{array}$ & 2 & 8 & 10 & 12 & 19 & 11 & 7 & 20 \\
\hline Costa Rica & - & - & - & - & - & 4 & 2 & 2 \\
\hline Croácia & - & 1 & - & 1 & - & - & - & - \\
\hline Cuba & - & - & - & - & - & - & - & 2 \\
\hline Dinamarca & 1 & 4 & 5 & 4 & 2 & 5 & 7 & 3 \\
\hline Egito & - & - & - & - & 1 & 1 & - & - \\
\hline Equador & - & 2 & - & 4 & 3 & 16 & 5 & 5 \\
\hline Escócia & - & - & - & 2 & 2 & 4 & 3 & 4 \\
\hline Eslováquia & - & - & - & - & - & - & - & - \\
\hline Eslovênia & - & - & - & 1 & - & - & - & - \\
\hline Espanha & 67 & 88 & 110 & 138 & 122 & 124 & 106 & 97 \\
\hline $\begin{array}{l}\text { Estados } \\
\text { Unidos da } \\
\text { América }\end{array}$ & 21 & 45 & 21 & 21 & 43 & 11 & 13 & 12 \\
\hline Estônia & 3 & - & - & - & - & - & - & - \\
\hline Finlândia & 4 & 6 & 3 & 7 & 9 & 8 & 5 & 5 \\
\hline França & 137 & 188 & 219 & 244 & 284 & 282 & 249 & 241 \\
\hline Grécia & - & 1 & - & - & - & - & - & - \\
\hline Honduras & - & - & - & - & - & - & - & 1 \\
\hline Hungria & 2 & 3 & 2 & - & 1 & - & 2 & 1 \\
\hline Índia & - & - & - & - & 1 & - & - & - \\
\hline
\end{tabular}




\begin{tabular}{|c|c|c|c|c|c|c|c|c|}
\hline Inglaterra & 6 & 7 & 17 & 12 & 29 & 18 & 25 & 24 \\
\hline Irã & - & - & 1 & - & - & - & - & - \\
\hline Irlanda & - & 1 & - & - & - & - & 4 & 4 \\
\hline $\begin{array}{l}\text { Irlanda do } \\
\text { Norte }\end{array}$ & - & - & - & 1 & 1 & 1 & - & - \\
\hline Israel & - & - & - & - & - & 3 & 2 & 2 \\
\hline Itália & 21 & 29 & 54 & 59 & 54 & 57 & 65 & 55 \\
\hline Japão & 6 & 11 & 15 & 21 & 34 & 18 & 30 & 21 \\
\hline Líbano & - & - & - & - & - & 1 & 1 & - \\
\hline Lituânia & - & - & - & - & - & - & 1 & - \\
\hline Marrocos & - & - & - & - & - & - & - & 1 \\
\hline México & 32 & 36 & 62 & 83 & 92 & 104 & 110 & 82 \\
\hline Moçambique & - & - & 2 & 4 & 6 & 2 & 3 & 3 \\
\hline Nicarágua & - & - & - & - & 1 & 1 & - & - \\
\hline Noruega & 3 & 4 & 6 & 4 & 2 & 1 & 4 & 5 \\
\hline $\begin{array}{l}\text { Nova } \\
\text { Zelândia }\end{array}$ & - & 1 & 1 & - & 1 & - & - & - \\
\hline $\begin{array}{l}\text { País de } \\
\text { Gales }\end{array}$ & - & - & - & - & - & 1 & - & - \\
\hline $\begin{array}{l}\text { Países } \\
\text { Baixos }\end{array}$ & 24 & 23 & 19 & 29 & 45 & 24 & 24 & 25 \\
\hline Paraguai & - & 5 & 6 & 4 & 6 & - & 1 & - \\
\hline Peru & 11 & 15 & 23 & 44 & 65 & 54 & 52 & 58 \\
\hline Polônia & - & 1 & - & 2 & 1 & 2 & 1 & 1 \\
\hline Porto Rico & - & 3 & - & - & - & - & - & - \\
\hline Portugal & 89 & 90 & 120 & 104 & 94 & 59 & 50 & 45 \\
\hline $\begin{array}{l}\text { República } \\
\text { Dominicana }\end{array}$ & - & - & - & - & 2 & 3 & - & - \\
\hline $\begin{array}{l}\text { República } \\
\text { Tcheca }\end{array}$ & 5 & 5 & 2 & 5 & 5 & 1 & 1 & 3 \\
\hline Romênia & - & - & 1 & - & - & - & - & - \\
\hline Rússia & 8 & 5 & 3 & - & - & - & 1 & 2 \\
\hline Sérvia & - & - & - & - & - & - & 1 & - \\
\hline Suécia & 8 & 12 & 8 & 6 & 12 & 8 & 13 & 19 \\
\hline Suíça & 4 & 6 & 6 & 12 & 19 & 12 & 19 & 16 \\
\hline Tailândia & - & - & - & 2 & 2 & - & - & - \\
\hline Taiwan & - & - & - & - & - & - & - & - \\
\hline Turquia & - & - & - & - & - & 4 & - & - \\
\hline Uruguai & 1 & 2 & 6 & 10 & 7 & - & 1 & - \\
\hline Venezuela & 6 & 1 & 1 & 2 & 1 & 7 & 3 & 10 \\
\hline Total & 703 & 938 & 1090 & 1255 & 1413 & 1244 & 1185 & 1136 \\
\hline
\end{tabular}

Fonte: AUCANI, 2017.

Conforme é possível notar, os números cresceram consideravelmente até 2014, mas o quadro passou por uma reconfiguração e os índices decresceram entre 2015 e 2017. Pode-se supor 
que essa realidade tenha se configurado em virtude das mudanças que as economias interna e externa do Brasil sofreram, bem como de uma série de escândalos ligados ao país e à sua imagem. Não obstante, a própria ciência brasileira, conforme descrito em artigo pulicado na Nature (ANGELO, 2017), vem passando por uma fase de muitos cortes, o que também justifica a queda na procura estrangeira pela USP.

Essa, entretanto, não é uma realidade que pode ser tomada como padrão geral. Em relação aos estágios de curta duração, por exemplo, note-se que os números oscilam. Eles cresceram até 2013, passando por um período de encurtamento, mas voltaram a subir entre 2015 e 2016, sofrendo nova queda apenas no ano de 2017 , conforme mostra a tabela a seguir:

\begin{tabular}{|c|c|c|c|c|c|c|c|c|}
\hline \multicolumn{9}{|c|}{ Curta Duração } \\
\hline País & 2010 & 2011 & 2012 & 2013 & 2014 & 2015 & 2016 & 2017 \\
\hline Alemanha & - & 3 & 1 & 3 & 3 & 6 & 2 & 6 \\
\hline Argentina & - & 1 & 2 & 4 & 9 & 7 & 5 & 1 \\
\hline Áustria & - & - & - & - & 1 & - & - & - \\
\hline Bélgica & - & - & - & - & - & - & 1 & 1 \\
\hline Canadá & - & - & - & - & 1 & 3 & 2 & - \\
\hline Chile & - & - & - & 4 & 3 & 1 & - & 4 \\
\hline China & - & - & - & - & - & - & - & 2 \\
\hline Colômbia & - & 4 & 15 & 26 & 26 & 15 & 22 & 15 \\
\hline Costa Rica & - & 1 & 1 & 2 & - & - & 1 & - \\
\hline Cuba & - & - & - & 1 & 1 & - & 1 & 1 \\
\hline Equador & - & - & 1 & 2 & 10 & 1 & 13 & 2 \\
\hline Escócia & - & - & - & 11 & 4 & - & - & - \\
\hline Espanha & - & - & 1 & 4 & 5 & 10 & 14 & 5 \\
\hline EUA & - & 14 & 16 & 21 & 14 & 28 & 28 & 18 \\
\hline Etiópia & - & - & - & - & - & - & - & 1 \\
\hline França & 1 & 1 & 3 & 13 & 8 & 13 & 16 & 8 \\
\hline Hungria & - & - & - & - & - & - & - & 1 \\
\hline Índia & - & - & - & - & - & - & - & 1 \\
\hline Inglaterra & - & - & 2 & 17 & 16 & 31 & 22 & 37 \\
\hline Irlanda & - & - & - & - & 1 & - & - & 1 \\
\hline $\begin{array}{l}\text { Irlanda do } \\
\text { Norte }\end{array}$ & - & - & - & - & - & 1 & - & - \\
\hline Itália & - & 3 & - & 3 & 2 & 4 & 8 & 6 \\
\hline Japão & - & - & - & - & - & 3 & 1 & 1 \\
\hline México & - & - & 3 & 12 & 3 & 9 & 14 & 4 \\
\hline Moçambique & - & - & - & - & - & - & - & 1 \\
\hline $\begin{array}{ll}\text { País } & \text { de } \\
\text { Gales } & \\
\end{array}$ & - & - & 2 & - & - & 1 & - & - \\
\hline $\begin{array}{l}\text { Países } \\
\text { Baixos }\end{array}$ & - & 1 & - & - & 3 & 1 & 5 & 3 \\
\hline
\end{tabular}




\begin{tabular}{l|c|c|c|c|c|c|c|c}
\hline Paraguai & - & - & - & - & - & - & 3 & - \\
\hline Peru & - & - & 3 & 16 & 17 & 28 & 40 & 37 \\
\hline Portugal & - & 1 & 6 & 4 & 7 & 2 & 4 & 6 \\
\hline Ruanda & - & - & - & - & - & - & - & 1 \\
\hline Suécia & - & - & 2 & 4 & - & 5 & - & 2 \\
\hline Suíça & - & - & - & 1 & - & 1 & - & - \\
\hline Turquia & - & - & - & - & - & - & 2 & - \\
\hline Uruguai & - & - & 1 & - & 2 & - & 3 & 1 \\
\hline Venezuela & - & - & 1 & - & - & - & - & - \\
\hline Total & 1 & 29 & 60 & 148 & 136 & 170 & 207 & 166 \\
\hline
\end{tabular}

Por outro lado, os convênios de duplo diploma apresentam uma realidade numérica consideravelmente próxima da descrita em relação aos intercâmbios: a demanda cresce até 2013, mas tem passado por decréscimo a partir de 2014, o que se mantém até 2017. A tabela da sequência é responsável pela síntese dessas informações.

\begin{tabular}{l|c|c|c|c|c|c|c|c}
\hline \multicolumn{1}{c}{ País } & $\mathbf{2 0 1 0}$ & $\mathbf{2 0 1 1}$ & $\mathbf{2 0 1 2}$ & $\mathbf{2 0 1 3}$ & $\mathbf{2 0 1 4}$ & $\mathbf{2 0 1 5}$ & $\mathbf{2 0 1 6}$ & $\mathbf{2 0 1 7}$ \\
\hline Alemanha & - & 1 & 3 & 3 & 2 & - & 3 & 6 \\
\hline Espanha & 1 & 1 & 1 & 1 & 4 & 2 & - & - \\
\hline França & 35 & 38 & 45 & 60 & 47 & 30 & 33 & 35 \\
\hline Itália & 1 & 2 & 5 & 7 & 6 & 3 & 5 & 13 \\
\hline Peru & - & - & - & - & - & 1 & 2 & 2 \\
\hline Portugal & - & - & - & - & 1 & 3 & 3 & 1 \\
\hline Total & $\mathbf{3 7}$ & $\mathbf{4 2}$ & $\mathbf{5 4}$ & $\mathbf{7 1}$ & $\mathbf{6 0}$ & $\mathbf{3 9}$ & $\mathbf{4 6}$ & $\mathbf{5 7}$ \\
\hline
\end{tabular}

Tabela III - Alunos, para obtenção de duplo diploma, na USP (2010 a 2017).

Fonte: AUCANI, 2017.

Diante dessas demandas e da parceria existente entre o programa governamental Idioma sem Fronteiras $(\mathrm{IsF})^{8}$ e a USP, a AUCANI fornece ensino a distância de diferentes línguas estrangeiras (chinês, espanhol, inglês, italiano), tanto a alunos brasileiros quanto àqueles que são provenientes de outros países.

\footnotetext{
${ }^{8}$ O Idioma sem Fronteiras tem objetivo de promover políticas linguísticas voltadas à internacionalização do Ensino Superior do Brasil, por meio da formação e capacitação de professores de línguas estrangeiras. Para isso, o programa fornece cursos online (de curta duração) em diversos idiomas, além de exames de proficiência e outros cursos presenciais que, em universidades cadastradas, tornam-se complementares para a formação de professores brasileiros.

Para mais informações, verificar o site do IsF: $\underline{\text { http://isf.mec.gov.br/programa-isf/entenda-o-isf }}$ Acesso em 18 out. 2018.
} 
No entanto, ainda são consideravelmente recentes as ações ligadas à internacionalização do idioma nacional. De acordo com informações concedidas pela professora Laura Izarra ${ }^{9}$, diretora adjunta de relações acadêmicas AUCANI, o ensino de inglês é o que se dá há mais tempo e de forma mais contundente, em virtude da alta procura, sobretudo por parte dos alunos brasileiros que estudam na USP. Além disso, o idioma é o único que possui curso presencial fornecido pela AUCANI.

Desde o início de 2016, porém, a agência também fornece um curso online de Português para Estrangeiros. Trata-se de uma iniciativa que, com base nos informes de chamadas realizadas em $2019^{10}$, atende a aproximadamente 1445 alunos e volta-se ao nível básico da língua. $\mathrm{O}$ objetivo desse curso é de permitir que o aluno estrangeiro, seis meses antes de vir morar no Brasil, familiarize-se com o idioma utilizado na maior parte das disciplinas e laboratórios da universidade.

Por outro lado, em outubro de 2017, a USP iniciou, ainda no âmbito da AUCANI e do IsF, por meio do Núcleo de Línguas do Idioma sem Fronteiras (NucLi-IsF), um centro formador de professores de Português como Língua Adicional (doravante, PLA). Um edital selecionou licenciandos da casa para se tornarem os responsáveis por uma turma presencial de ensino-aprendizagem de PLA. A partir disso, então, a agência pretende abrir dezoito turmas presenciais de quinze alunos, a fim de garantir que o PLA seja ensinado a um total de 216 alunos.

A AUCANI conta ainda com a iniciativa IFriends, por meio da qual, um aluno USP de graduação se voluntaria a receber e auxiliar um estudante estrangeiro. Desde 2011, esse programa de voluntariado visa que os estrangeiros sejam integrados à comunidade universitária, o que também objetiva o seu acesso à língua portuguesa, embora isso ocorra fora do âmbito institucional ligado ao ensino de caráter oficial.

Em relação às iniciativas da USP, também não se pode deixar de mencionar o trabalho que é desenvolvido pelo Centro de Línguas da Faculdade de Filosofia, Letras e Ciências Humanas, o qual, por sua vez, fornece os seguintes cursos de PLA: Redação para Estrangeiros; e Conversação e produção de texto em Português língua estrangeira), além de testes de

\footnotetext{
${ }^{9}$ Entrevista concedida no dia 27 de setembro de 2017, na sede da AUCANI no campus USP da capital.

${ }^{10}$ Para mais informações, verificar o site da AUCANI: http://www.usp.br/internationaloffice/ Acesso em 17 mar. 2019.
} 
proficiência no português brasileiro - voltados a mestrandos/doutorandos já matriculados na USP e a candidatos estrangeiros aos programas de pós-graduação da instituição.

Conforme mostram as tabelas presentes nas páginas anteriores, a demanda pela aprendizagem de PLA é grande na USP. Somando os alunos estrangeiros que a instituição recebeu, apenas no ano de 2017 - nas três modalidades citadas, tem-se um total de 1359 estudantes. Contudo, a política linguística da USP, ligada à internacionalização do idioma oficial do Brasil, ainda não consegue abarcar essa realidade de forma presencial e em níveis superiores de aprendizagem idiomática.

Sem dúvidas, as políticas linguísticas, do Centro de Línguas e as políticas recentemente implantadas pela AUCANI, permitem antever uma mudança de ventos: mais alunos serão atendidos, o que já parece esclarecer que a demanda e a importância da questão foram notadas no contexto institucional.

Conforme exposto por Laura Izarra (2017), essas ações demarcam não uma tendência política relacionada à gestão de uma reitoria em específico, mas um plano de melhorias que a USP tem assumido como essencial e perene. Contudo, é importante ressaltar que, embora o caminho percorrido seja de extrema importância, demandas numéricas urgentes ainda se impõem.

Diante do fato de que essa universidade está entre as mais importantes do contexto nacional, o que, sem dúvidas, justifica a sua procura por parte de alunos estrangeiros, é importante considerar que uma política linguística duradoura, para a promoção do ensino de PLA, realmente é uma demanda que se apresenta com caráter de urgência.

Nesse âmbito, é importante viabilizar ações mediante participação efetiva dos recursos humanos que a USP possui na área de PLA (professores da casa e pós-graduandos), a fim de que as políticas desenvolvidas sejam pensadas pelos que detêm um saber especializado, o que potencializará a internacionalização do português brasileiro e auxiliará a vida acadêmica dos estudantes estrangeiros que vêm até a instituição. Por fim, e a partir desses dados e ideias, o próximo tópico retoma o objetivo do estudo e apresenta algumas considerações que visam sintetizar a discussão aqui realizada.

\section{Considerações Finais}


O objetivo deste artigo foi apresentar um estudo de caso ligado à Universidade de São Paulo, por meio de uma discussão que relacionou dados numéricos da Agência USP de Cooperação Acadêmica e Internacional (AUCANI), referentes ao número de alunos estrangeiros recebidos por essa universidade, às ações que ela executa no sentido de ensinar PLA no campus da capital.

De modo geral, os dados permitem notar que a gestão universitária tem se ocupado de importantes iniciativas ligadas ao ensino de língua portuguesa no processo de internacionalização doméstica, seja via AUCANI ou via Centro de Línguas. Por outro lado, também permitem considerar que as ações ainda não são suficientes em termos quantitativos e em relação a abarcar níveis de ensino mais avançados do português brasileiro.

Quando se considera que, por meio das línguas, os falantes agem socialmente, entende-se que ensinar PLA, no interior das universidades brasileiras, é um imperativo. No caso da USP especificamente ou de qualquer outra instituição, ensinar a língua portuguesa é essencial para que os estudantes estrangeiros consigam ter êxito não somente na vida acadêmica, mas também na participação cidadã em uma escala mais ampla.

Assim, e como forma de fechamento, entende-se que a ação de ensinar a língua portuguesa a estrangeiros que vêm estudar nas universidades brasileiras deve ser posta como parte constitutiva da internacionalização das instituições. Isso, antes de qualquer outra coisa, é uma forma de acolhimento e de tentar democratizar o conhecimento.

\section{Referências Bibliográficas}

ANGELO, C. Brazilian scientists reeling as federal funds slashed by nearly half. Nature, abr. 2017.

Disponível

em: https://www.nature.com/news/brazilian-scientists-reeling-as-federal-funds-slashed-by-nearly$\underline{\text { half-1.21766 }}$

Acesso em: 19 out. 2017.

ALBUQUERQUE, A.; ESPERANÇA, J. P. El valor económico del portugués: lengua de conocimiento con influencia global. Madri: Real Instituto Elcano, p. 1-15, 2010.

Disponível em: http://biblioteca.ribei.org/2023/1/DT-26-2010.pdf

Acesso em: 3 out. 2018.

BOURDIEU, P. A economia das trocas simbólicas. São Paulo: Perspectiva, 6 ed., 2007. 
CARVALHO, S. da C. Políticas de promoção internacional da língua portuguesa: ações na

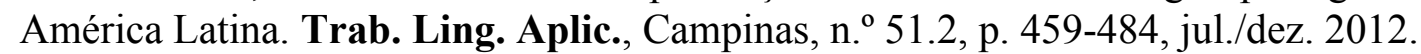

Disponível em: http://www.scielo.br/pdf/tla/v51n2/a10v51n2.pdf

Acesso em: 8 set. 2018.

HALL, S. A identidade cultural na pós-modernidade. $11^{\mathrm{a}}$ ed. Rio de Janeiro: DP\&A Editora, 2006. 102 p.

KNIGHT, J. A Shared Vision? Stakeholders Perspectives on the Internationalization of Higher Education in Canada. Journal of Studies in International Education, v. 1, Spring, p. 27-44, 1997.

KNIGHT, J.; DE WIT, H. Strategies for Internationalisation of Higher Education: historical and conceptual perspectives. Amsterdam: European Association for International Education, 1995.

LIMA, M. C.; MARANHÃO, C. M. S. de A. O sistema de educação superior mundial: entre a internacionalização ativa e passiva. Avaliação, Campinas; Sorocaba, v. 14, n. 3, p. 583-610, 2009.

MOROSINI, M. C. Estado do conhecimento sobre internacionalização da educação superior conceitos e práticas. Educar, Curitiba, $\mathrm{n}^{\circ}$ 28, p. 107-124, 2006.

Disponível em: https://www.redalyc.org/pdf/1550/155013353008.pdf

Acesso em: 11 ago. 2018.

OLIVEIRA, G. M. O lugar das línguas: A América do Sul e os mercados linguísticos na Nova Economia. Synergies Brésil, $n^{\circ}$ 1, p. 21-30, 2010.

Disponível em: http://gerflint.fr/Base/BresilSPECIAL1/gilvan.pdf

Acesso em: 20 ago. 2018.

. Política linguística e internacionalização: a língua portuguesa no mundo globalizado do século XXI. Trab. Ling. Aplic., Campinas, n. ${ }^{\circ}$ 52.2, p. 409-433, jul./dez. 2013.

Disponível em: http://www.scielo.br/pdf/tla/v52n2/a10v52n2.pdf

Acesso em: 27 ago. 2018.

QIANG, Z. Internationalization of Higher Education: towards a conceptual framework. Policy Futures in Education, v. 1, n. 2, p. 248-270, 2003.

Disponível em: https://journals.sagepub.com/doi/pdf/10.2304/pfie.2003.1.2.5

Acesso em: 27 ago. 2018.

RODRIGO-ALSINA, M. Espacios de la interculturalidad. Elementos para uma comunicación intercultural. Revista Cidob d'Afers Internacionals, Barcelona, no 36, 1997. p. 11-21.

SILVA, S. D. J. Descendentes de falantes de português nas classes de PFOL: um público que merece atenção específica. In: SÁ, Rubens Lacerda (Org.). PFOL (Português para Falantes de Outras Línguas): interculturalidade, inclusão social e políticas linguísticas. Campinas: Pontes, $1^{\mathrm{a}}$ ed., 2016. p. 87-115.

TAYLOR, J. The Management of Internationalisation in Higher Education. 
Internationalisation of European Higher Education: Raabe, 2010.

VEIGA, R. B. Internacionalização das Instituições de Ensino Superior em Portugal: proposta de metodologia para construção de indicador do grau de internacionalização. Mestrado em Negócios Internacionais. Dissertação - Instituto Politécnico de Leiria, Leiria. 2011.

Disponível

em:

https://iconline.ipleiria.pt/bitstream/10400.8/544/1/MNI\%20Rita\%20Veiga.pdf

Acesso em: 16 mar. 2019.

WARNIER, J. P. Arte zen versus Titanic. In: WARNIER, J. P. A mundializaçãa da cultura. Bauru, SP: EDUSC, 2000. p. 11-32.

Recebido em 17/03/2019. Aceito em 08/07/2019. 